\title{
On The Mathematical Modelling Of Population Dynamics and Growth of Clarias Glariepinus in a Pond
}

\author{
Udaya C.O., Eze E.O And Onyema, M.K. \\ Department Of Mathematics Michael Okpara University Of Agriculture, Umudike-Umuahia, Abia State.
}

\begin{abstract}
We considered the equation of population dynamics and interacting growth of Clarias glariepinus (catfish) in a concrete pond. We proposed a logistic model using a combination of Euler and Runge- Kutta methods as the "best" approach in approximating the increases in the yield of the fish according to time. The results obtained showed that it allowed a choice of optimal regimes of aeration, feeding and fertilization of the fish for different climatic conditions in order to maximize the yield. We concluded that these approaches were the best in determining maximum yields of the fish in a concrete pond when tested for growth, stocking densities and harvesting processes.
\end{abstract}

Keywords: Population Dynamics and Growth, Clarias glariepinus, Runge- Kutta method, Euler's method, Logistic model.

\section{Introduction}

The objective of this paper is to propose and analyze a deterministic mathematical model for the population Dynamics and interacting growth of Clarias gariepinus (catfish) in a concrete pond. Interest in how population tends to grow was stimulated in the $18^{\text {th }}$ century when Thomas Malthus proposed a law which is often called the Malthusian law. Suppose the population at some given time $t=t_{0}$ is $p_{0}$ and at some time $t=t_{1}$ is $p$. Let $b$ and $d$ be birth and death rates respectively then,

$\frac{d p}{d t}=b p-d p$
$\frac{d p}{d t}=(b-d) p$
$\frac{d p}{d t}=k p$

where $k=b-d$ is a positive constant for growth.

$$
p\left(t_{0}\right)=p_{0} ; t_{0} \leq t \leq t_{1}
$$

Integrating, we get

$\ln p=k t+c$

where $c$ is a constant

Applying the initial condition $p\left(t_{0}\right)=p_{0}$, it then follows that

$\ln p=k t+\ln p_{0}-k t_{0}$

$\ln \frac{p}{p_{0}}=k\left(t-t_{0}\right)$

The above is equally called the Malthusian model of population growth and this he believed was valid for relatively small population (of human, animals, bacterial, etc.). From the above equation, it can be deduced that $b>d$, the population grows exponentially with time while $b<d$, it dies out.

Giordano et al (1997), Malthusian model can be modified to obtain a model in which a self-limiting process operates when a population becomes large. In general $b$ is a monotonic decreasing function of $p$, hence we can write

$\frac{d p}{d t}=[b(p)-d(p)] p=p k(p)$

Chude (2001) Growth refers to quality change in size or number with time and it is dependent on food consumed, it is being triggered off by the available chemical energy bound up in the food ingested by the organism. This food provides energy to be used, for biosynthesis, storage and metabolic processes therefore, even when density is not limiting, growth still depends on food and food type. Olaniyan (1975) was concerned with increase in production. Understanding the major courses of growth variation is crucial for the success of fish farming, since its reduction contributes to maximal production efficiency, reduced food waste and improves water quality. In fish, growth is influenced primarily by population density and food supply. The other factors are space, temperature, size of the individual, climate and even other organisms interacting with the fish within the same environment. The effect of population density or crowding stress on fish is two-fold. It is inhibitory to growth but catalytic to mortality, the later early in life but the former later in life. Martin et al (2005) reported that individual variation on growth efficiency is important in determining growth rate. Eyo (2003) investigated the acceptability diet, growth performance and cost-benefit analysis for Clarias gariepinus fed varied diets 
enriched with dietary lipid from plants and animals sources. The result indicated the enrichment of Clarias rariepinus fingerlings diet with lipids which enhances the acceptability of diet, the best acceptable diet being olive-oil enriched diet. The survival of Clarias gariepinus and the growth during the culture period was recorded according to the formula:

$\%$ survival $=\frac{\text { Number of survivors }}{\text { Total number of fish stocked }} \times \frac{100}{1}$

Specific growth rate was calculated for the evaluation of fish performance using the formula. $\frac{\ln (\text { frial mean weight })-\ln (\text { initial mean weight })}{\text { days feed }} \times \frac{100}{1}$

\section{The Model}

This model applies to growth and decay processes, interacting populations etc. let us consider a catfish habitat in an aquatic ecosystem, consisting of reserved and unreserved areas. In modeling it is considered that no fishing is permitted in the reserved zone; while the unreserved area is the open access fishery zone. Let $X(t)$ and $y(t)$ be the respective biomass densities of the same fish population inside the unreserved and reserved areas, respectively at a time, $t$. Let the fish sub population of the unreserved area migrate into reserved area at a rate $\delta_{1}$ and the fish subpopulation of the reserved area migrate into unreserved area at a rate $\delta_{2}$. Let $E$, be the total effort applied for harvesting the fish population in the unreserved area. We assume that in each zone, growth of fish population followed a logistic model. Keeping this in view the dynamics of fish subpopulations in unreserved and reserved areas may be governed by the following autonomous system of differential equation

\subsection{THE GOVERNING EQUATION}

Our governing autonomous differential equation is the logistic equation given by

$\frac{d x}{d t}=\alpha X\left(1-\frac{x}{k}\right)-\delta_{1} x+\delta_{2} y-q E_{x}$

$\frac{d y}{d t}=S_{y}\left(1-\frac{y}{h}\right)+\delta_{1} x-\delta_{2} y$

Where $r$ and $s$ are the intrinsic growth rates of fish subpopulation inside the unreserved and reserved areas respectively, $k$ and $h$ are the carrying capacities of fish species in the unreserved and reserved areas respectively $q$ is the catch coefficient of fish species in the unreserved area. The parameters $r, s, q, \delta_{1}, \delta_{2}, k$ and $\alpha$ are assumed to be constants.

\section{MODEL FORMULATION-NUMERICALISATION}

\section{Methodology}

The previous simple model is now extended to take into account a more realistic estimate by applying numerical solution to test for the growth rate of the fish by using Euler and Runge -Kutta methods. Also, we will investigate the harvesting strategies with modified effort function.

\section{Main Results}

Using Euler's method to check for the growth rate of fish size ranging from $(0-2)$. We try to find an approximate value of $t$ corresponding to $N=2$.

Given that $\frac{d N}{d t}=N+2 t$

When $t=1$ and $N=1$, we have that

$F(N, t)=N+2 t$

$t_{n+1}=t_{n}+h f\left(N_{n}, t_{n}\right)=t_{n}+0.1(N+2 t)$

\begin{tabular}{|c|c|c|c|}
\hline$N$ & $t($ days $)$ & $N+2 t=\frac{d N}{d t}$ & old $t+0.1 \frac{d N}{d t}=$ New $t$ \\
\hline 1 & 1 & 3 & $1+0.1(3)=1.30$ \\
\hline 1.1 & 1.3 & 3.70 & $1.3+0.1(3.7)=1.67$ \\
\hline 1.2 & 1.67 & 4.45 & $1.67+0.1(4.45)=2.12$ \\
\hline 1.3 & 2.12 & 5.54 & $2.12+0.1(5.54)=2.67$ \\
\hline 1.4 & 2.67 & 6.74 & $2.67+0.1(6.74)=3.34$ \\
\hline 1.5 & 3.34 & 8.18 & $3.34+0.1(8.18)=4.16$ \\
\hline 1.6 & 4.16 & 9.92 & $4.16+0.1(9.92)=5.15$ \\
\hline 1.7 & 5.15 & 12.00 & $5.15+0.1(12.00)=6.35$ \\
\hline 1.8 & 6.35 & 14.50 & $6.35+0.1(14.50)=7.80$ \\
\hline 1.9 & 7.80 & 17.50 & $7.80+0.1(17.50)=9.95$ \\
\hline 2.0 & 9.55 & 21.10 & $9.55+0.1(21.10)=11.66$ \\
\hline
\end{tabular}

We will make use of Runge- kutta method to test also for the Growth Rate. The test was carried out for the fisheries in the pond to investigate if the approximate value of time $t$ varies with the population of fish and also the growth rate with respect to the amount of time given. 
We recall our equation (4.1)

$$
\frac{d N}{d t}=N+2 t
$$

Our job here is to try to find an approximate value $t$ corresponding to $N=2$ given (4.1) which is

$\frac{d}{d t}=N+2 t$

When $t=1$ and $N=1$

Remark: The Runge- Kutta method is a modified Euler's method formula. Here, we have

Invoking equation $(4.2)$

$$
N_{0}=1, t_{0}=1, h=0.1
$$

$$
\begin{gathered}
f(N, t)=N+2 t, f\left(p_{0}, t_{0}\right) \\
=1+2(1) \\
=3 \\
K_{1}=0.1 \times 3=0.3 \\
K_{2}=h f\left(N_{0}+h, t_{0}+k_{1}\right) \\
=0.1 \times 1(1+0.1+1+0.3) \\
=0.1(1.1+1.3) \\
=0.1(2.4) \\
=0.24 \\
t_{1}=1+\frac{1}{2}(0.3+0.244) \\
=1+\frac{1}{2}(0.544) \\
t_{1}=1+0.272 \\
=1.272 \\
\sim 1.3
\end{gathered}
$$

\section{Discussion}

1. We discovered that the Euler and Runge Kutta methods are the best approach for determining the maximum yields of the fish.

2. We observed from our result that the population of fish increases according to time.

3. We discovered that when $t$ corresponds to $P=2$, we obtain 9.55 and the total population with respect to time is given by 17.50

The results obtained shows that it allowed a choice of optimal regimes of aeration feeding and fertilization of the fish for different climatic conditions in order to maximize their yields.

\section{Conclusion}

From the fore goings, we can conclude that both the Runge-Kutta and Euler's methods as investigated is the best approach in maximizing the yields of the fish in a concrete pond, when tested for growth, stocking densities and harvesting processes.

\section{References}

[1]. Aluko, P. I.; Nlewadim, A.A and Aremu, A. (2001); Observation of fry cannibalism in clarias gariepinys (Burchell, 1822), Journal of aquatic science 16:1-6

[2]. Boyce, E. W., Diprime C. R. (1986); Elementary differential Equations, John Wiley and sons Inc. N.Y.

[3]. Bronson, Richard (1994); Theory and Problems of Differential Equations, Schaum's outline series, $2^{\text {nd }}$ Edition, McGraw - Hill Inc. Singapore

[4]. Fogrel, M. (1999); The statistics problem solver. Research and Education Association, USA, 768 - 775pp

[5]. Frauenthal, JC (1980); Introduction to population Modeling, Birkaus, Boston.

[6]. Giordano, F. R., Weir, M.D., Fox, W.P. (1997); A First Course in mathematical modeling, $2^{\text {nd }}$ Edition, brooks/cole publishing company USA

[7]. Hogendoorn, H. (1997); Controlled propagation of African Catfish, (clarias glariepinus). Feeding and growth of fry aquaculture $21: 233-241$

[8]. Hornby, S.A. (1998); Oxford Advanced Learner's Dictionary, Oxford University Press, New York.

[9]. SAS Institute incorporated (1991); SAS system of linear models, $3^{\text {rd }}$ edition Cary, NC, USA

[10]. Verreath J. and Van Tongeren M. (1998); Weaning time in clarias gariepinus (Burchell) Larvae, Aquaculture 83: $81-88$ 